\title{
Chilean geo client application for disasters
}

\author{
Rodrigo F. Suárez, ${ }^{\mathrm{a}}$ Lucia Lovison, ${ }^{\mathrm{b}}$ Martinus Potters ${ }^{\mathrm{c}}$ \\ ${ }^{a}$ Universidad Técnica Federico Santa María, rodrigo.suarez@usm.cl \\ ${ }^{b}$ Afriterra Foundation, lovison@afriterra.org \\ ${ }^{c}$ Universidad Técnica Federico Santa María,martinus.potters@usm.cl
}

\begin{abstract}
The global network of the Group on Earth Observation, GEO, connects all kinds of professionals from public and private institutions with data providers, sharing information to face the challenges of global changes and human development and they are creating a Global Earth Observation System of Systems (GEOSS) to connect existing data infrastructures.
\end{abstract}

A GEOSS Architecture Implementation Pilot Project for Disasters in Chile (AIP-8) was created as part of a capacity building initiative and representatives of different national agencies in Chile, along with international experts, formed a GEOSS Capacity Building Working Group (Lovison et al, 2016).

Consistent with the objectives of GEOSS AIP -8 Chile, we developed and implemented a prototype service based on web services, mobile applications and other communication channels, which allows connecting different sources of information, aiming to reduce population vulnerability to natural disasters such as: earthquakes, flooding, wild fires and tsunamis, which is presented here.

The GEO Chile client application is a JavaScript application using GEODAB brokering services, GIS technology and disaster information provided by national and international disaster services, including public and private organizations, where cartography becomes fundamental as a tool to provide realism and ubiquity to the information. Seven hotpots are targeted: Calbuco, Copahue and Villarrica volcanoes areas, Valparaíso city, which is frequently a victim of wildfires in the zone where population meets forest and Iquique, Illapel and Talcahuano, areas frequently struck by earthquakes and tsunamis.

Keywords: Chile, disaster management, mobile application, capacity building, data sharing, international initiative, cartographic applications, earth observation, geographic systems.

\section{Introduction}

The Group on Earth Observation, GEO, "... is a partnership of more than 100 national governments and in excess of 100 Participating Organizations that envisions a future where decisions and actions for the benefit of humankind are informed by coordinated, comprehensive and sustained Earth observations." (GEO, 2017)

The global network of GEO connects all kinds of professionals from public and private institutions with data providers, sharing information to face the challenges of global changes and human development.

In order to share information under common standards, GEO is creating GEOSS, a Global Earth Observation System of Systems, connecting existing infrastructures, inviting more members to share their data and creating capacities where they are needed.

A GEOSS Common Infrastructure, GCI, will connect the information from data provider systems with users, providing data in all Social Benefit Areas structured in the GEOSS Portal (agriculture, biodiversity, climate, disasters, ecosystems, energy, health, water and weather). As part of a capacity building initiative, a GEOSS Architecture Implementation Pilot Project for Disasters in Chile (AIP-8) was created and representatives of different national agencies in Chile, along with international experts, formed a GEOSS Capacity Building Work Group.

The national agencies include the Ministry of Foreign Affairs, leading the Chilean GEO group; Ministry of National Property, with the Geospatial Data Infrastructure; Ministry of Interior and Public Safety, with its office for national emergencies ONEMI; Ministry of Agriculture, with its National Forestry Corporation CONAF; Chilean Air Force, with its Aerophotogrammetric Service, SAF, Chilean Navy, with its Hydrographic and Oceanographic Service, SHOA; General Directorate of Civil Aviation, with its Directorate of Meteorology; the National Geology and Mining Service SERNAGEOMIN; the Natural Resource Information Center, CIREN; the University Universidad de Chile, with its National Seismological Center, CNS; and the University Universidad Técnica Federico Santa María, with its Center for Aerospace Applications.

The objective of the AIP-8 project is to develop an application that allows the dissemination of useful information in order to facilitate decision taking related to natural disasters, both in terms of managing authorities, and at the level of the general public, based on a serviceoriented data architecture, which is based mainly on the 
use of sensors of different types (land, water, satellite, meteorological and others being available). The idea is to make use of the database of the GEOSS system and its geoportal.

In this scenario, cartography becomes fundamental as a tool to provide realism and ubiquity to the information. All the data must be arranged in geographic information systems, where the exact location of specific points will be displayed and characterized with local information in order to provide useful data for the disaster management and mitigation.

\section{The Disasters in Chile}

Chile is a place of earthquakes and the population is aware of this issue.

On the other hand, natural disasters are inevitable, so the idea is to provide tools to mitigate personal and socioeconomic effects and to help prevention, response and recovery in order to reduce the vulnerability.

The largest earthquake recorded in modern history occurred in Chile, May 22, 1960 (fig.1).

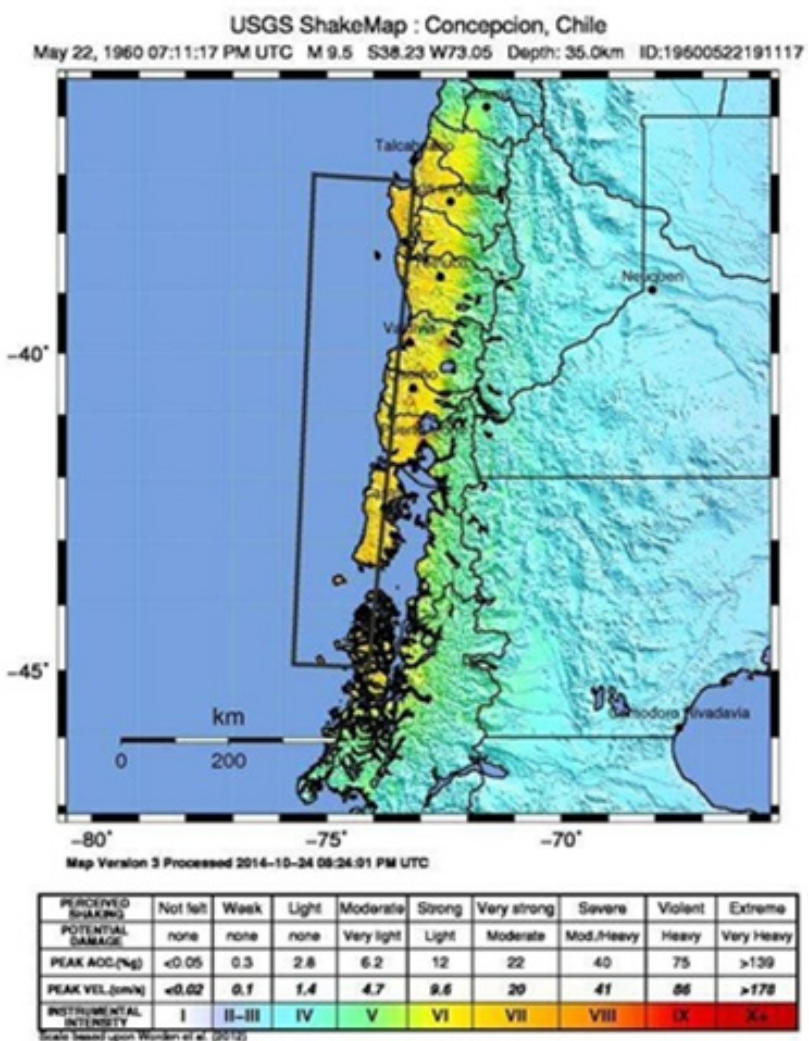

Figure 1 USGS ShakeMap for the May 22, 1960 Valdivia earthquake, which at an estimated magnitude of 9.5, is the strongest earthquake ever recorded.(Source: USGS).

On February 27, 2010, an 8.8 magnitude earthquake affected the central zone of Chile with high economic losses.(fig.2)

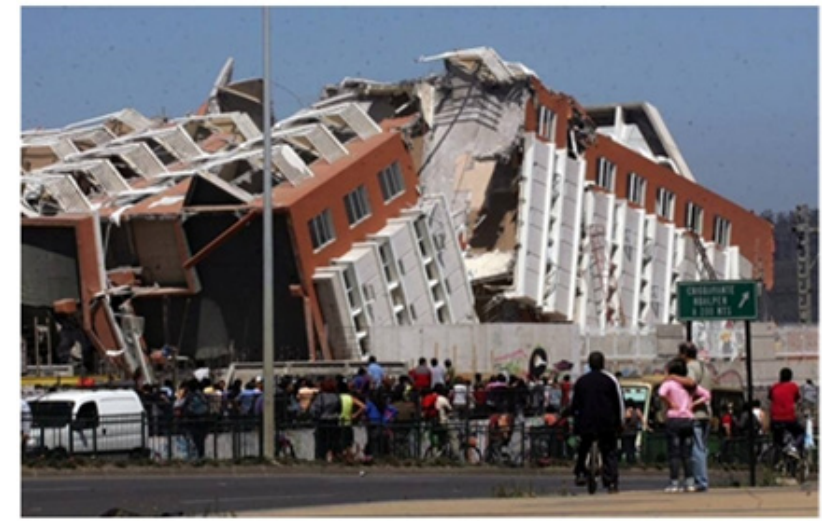

Figure 2 February 27, 2010, 8.8 magnitude earthquake, Chile. (Source: www.taringa.net)

On September 16, 2015, Chile was again struck by an 8.3 magnitude earthquake, this time generating a tsunami (fig.3)

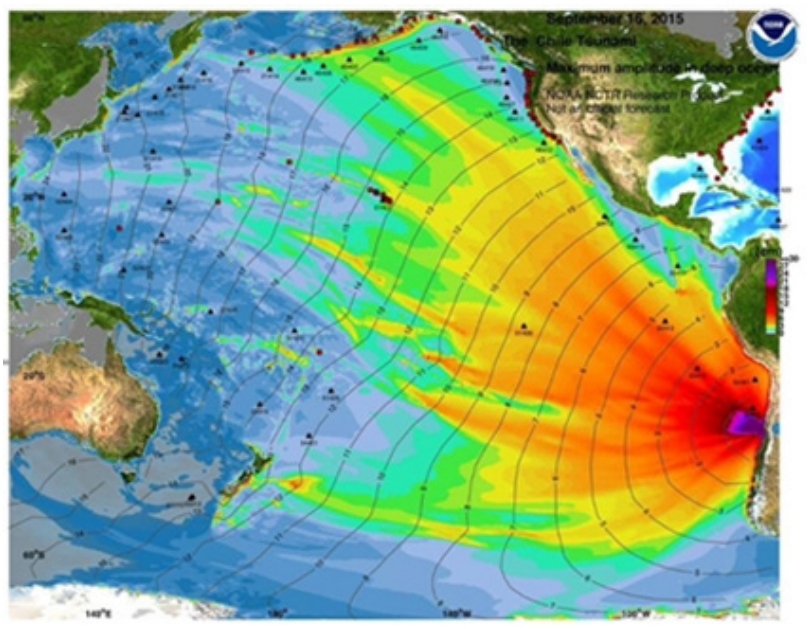

Figure 3 Tsunami waves after 2015 earthquake in Chile (Source: sanfrancisco.cbslocal.com)

The tsunami affected different coastal places in Chile and in the Juan Fernandez Island, causing personal and economic losses.

Chile is part of the so called "Pacific Ring of Fire" with near 90 actives volcanoes, some of them shown in figure 4. Located at the border between the Nazca plate and the South American plate, the country is between the Pacific Ocean and the Andes mountains, being frequently affected by earthquakes and volcanic eruptions and subsequent tsunamies. 


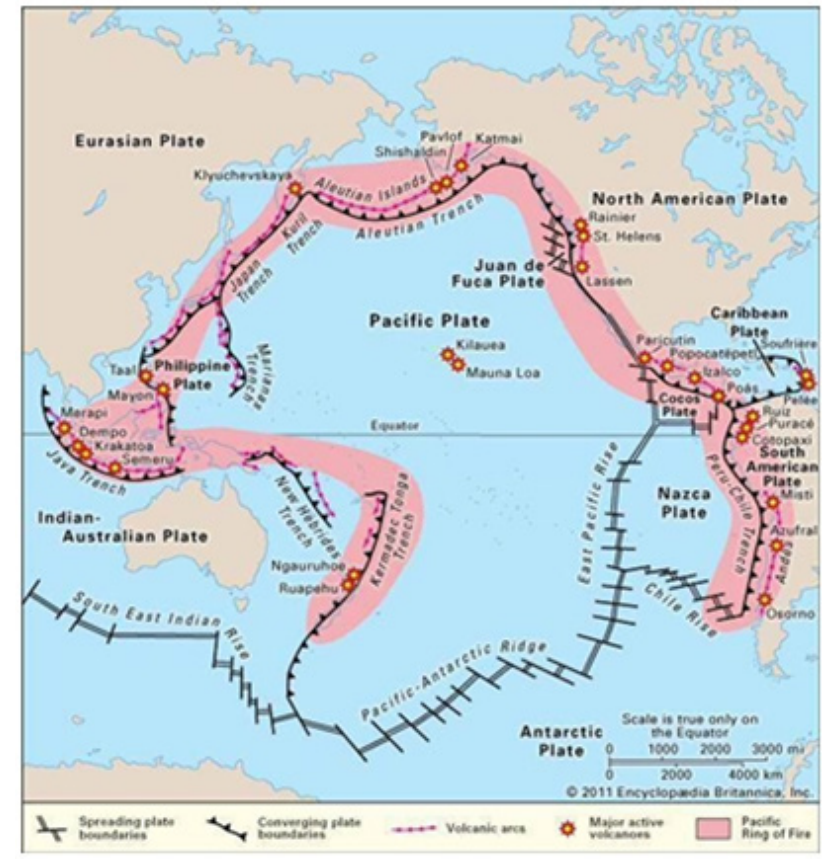

Figure 4 Pacific Ring of Fire (Source: Encyclopædia Britannica. Inc.)

Figure 5 shows one impressive eruption that occurred in 2015, when the Calbuco volcano launched a $12 \mathrm{~km}$. high ash column affecting cities in Chile and Argentina, as well as the commercial air traffic and agricultural activities.

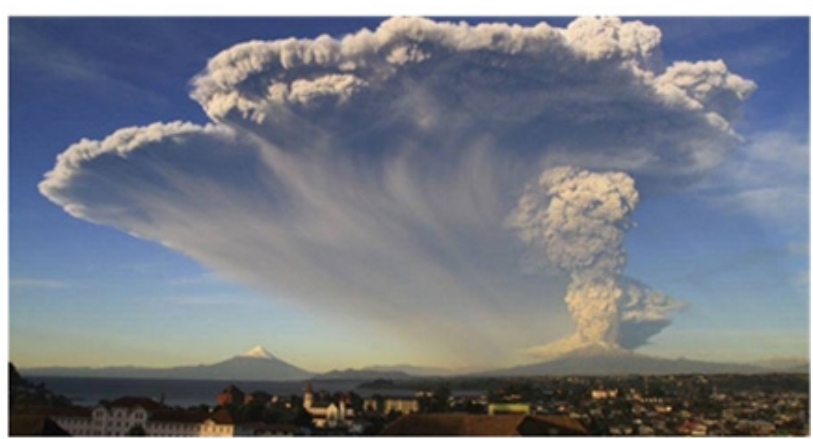

Figure 5 Eruption of Calbuco, 2015. (Source: Carlos Gutierrez, AP)

Wildfires are also a frequent source of disasters in Chile. Some of them affecting zones where wild and urban areas are too near, like in the hills around the city of Valparaiso. Some wild fires are due to human interaction with nature; but once initiated, they become as wild as nature determines and their effect on population can be equally severe.

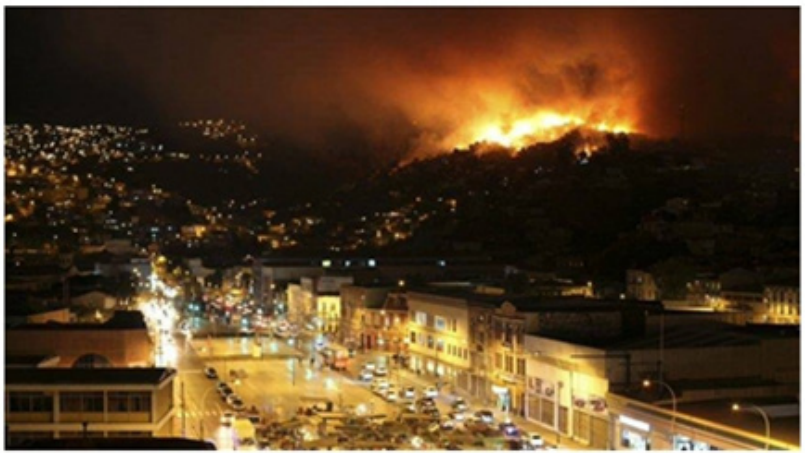

Figure 6 Wild fires near Valparaiso City, April 2014. (Source: Cesar Pincheira/Reuters)

\section{The Client Application}

In order to create access to the information, GEOSS provides a single internet gateway, powered by the GEO Discovery and Access Broker, DAB, developed by the Consiglio Nazionale delle Ricerche, CNR, and applying the brokering approach for multidisciplinary interoperability (Nativi et al, 2013; Nativi et al, 2012; Nativi et al, 2011).

The GEO DAB provides broker components for discovery, access and semantics-enabled search (Santoro et al, 2012) functionalities and a resource registration tool allowing users and data providers to share their knowledge and experiences.

We used the tools provided by the GEO DAB to create a Client Oriented Application, able to find and retrieve information from the GEOSS Portal, concerning different types of disasters in Chile.

The main objective of the AIP-GEO Chile Disaster initiative is to align with other regional and global initiatives within GEO, in order to develop and implement prototype services according to national priorities and to develop interoperable connections within and outside the continent through GEO data sharing principles, spatial standards, open source data and software in order to reduce vulnerability of the population to disasters.

Inside Chile, we want to provide means for the communication and sharing of data between different agencies, so they can better coordinate and concentrate their efforts during disaster management.

There are also objectives outside the country, related with the integration of other contributions and activities related with disaster risk management.

While working with national agencies, we realized that there are different criteria and policies related to the management of disasters that must be taken into account, so the client application will be a helpful tool not an interfering one; but improving the effectivity of local procedures.

So, consistent with the objectives of GEOSS AIP -8 Chile, we developed and implemented a prototype service based on web services, mobile applications and other communication channels, which allows connecting different sources of information, aiming to reduce 
population vulnerability to natural disasters such as: earthquakes, flooding, wild fires and tsunamies.

It is a JavaScript application, a tool for risk reduction using GEODAB brokering services, GIS technology, Cartography and disaster information provided by national and international disaster services, including public and private organizations and it is based on the following structure:

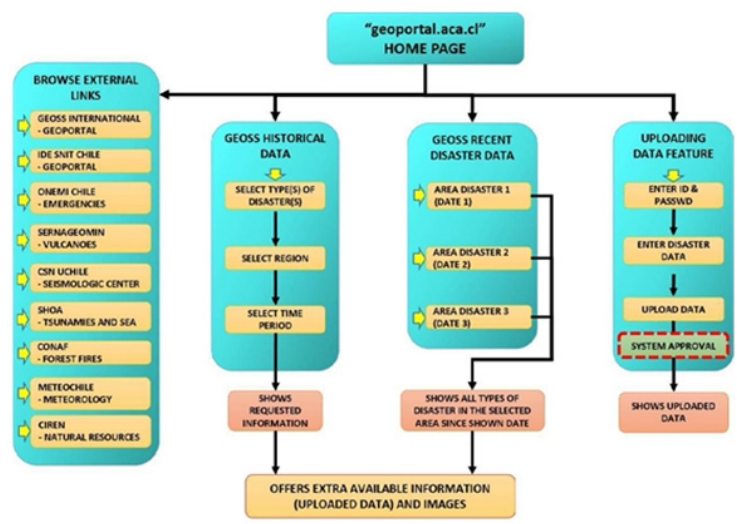

Figure 7 General structure of the Chilean Geo client application for disasters. (Source: Chile GEO Capacity Working Group)

The application facilitates the access to different data providers and includes a specific browsing capability inside the GEOSS portal.

\subsection{GEOSS Historical Data}

As a first step, the basic application is browsing historical information, according to the parameters entered by the user including the type of disaster, the region (or some specific location) in Chile and the selected period.

\subsection{GEOSS Recent Disaster Data}

This function is intended to be present, as a default, when just opening the application, offering all the data available of all kinds of disasters for the last three area events occurred in the last 48 hours. Thus, the user will select which one of the recent disaster areas he wants to examine and the application will report all the information, concerning all different types of disasters, concerning the last event occurred in the selected area.

Therefore, when selecting the last recent event in a specific location, the user will receive information on earthquakes, fires, volcanoes and floods affecting the area in the last 48 hours.

The idea is to be able to have a complete vision of the complexity of a disaster area when looking for information to help decision-making.

\subsection{The Uploading Data Feature}

In the complete version, the users will have the capability for uploading their own images and comments for an ongoing situation, so enriching the information with a local view of the events.

This will allow local authorities to upload vital information as a complement for the decision making process, closing the sharing circle.

\section{The Results}

The application is already developed in a first stage and provides a user interface to select the parameters for the historical navigation.

As by the beginning of 2017, entering the website "geoportal.aca.cl" a bilingual (Spanish and English) page offers to select the parameters for the GEOSS Historical Data. The application will browse the IRIS database in the GEO portal, using the semantic-enabled search developed by Mattia Santoro (Santoro et al., 2012).

The information is presented in text, as it is in the data base,

A cartographic reference is included, in the form of a Google Map/Google Earth interactive map, where the searching zones and the event sites are displayed.

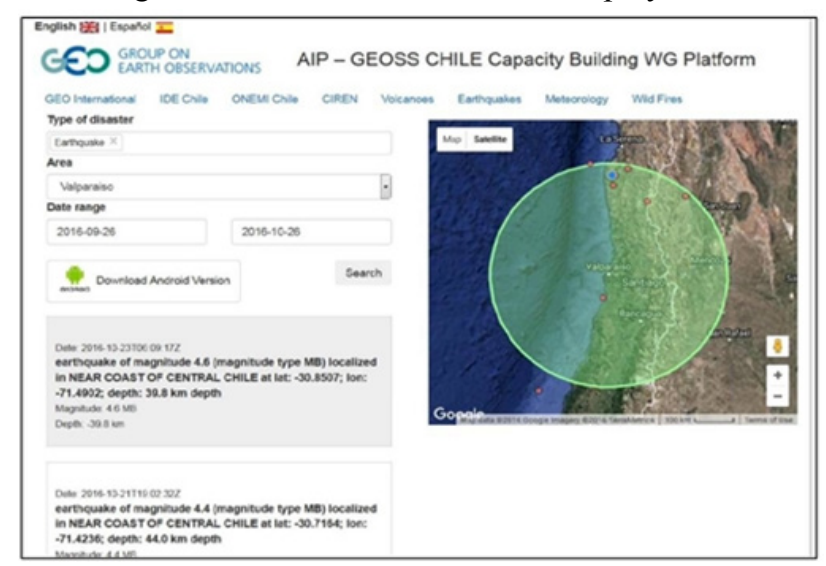

Figure 8 Chilean GEO Client Application for Disasters website. (Source: geoportal.aca.cl).

The AIP-GEO Chile initiative seeks to continue working and developing the client application, applying spatial data standards and the GEO sharing principles to the case of disasters. The application will need to be tested and improved with user evaluations.

There is much work to be done in terms of standardization of data and interoperability of different systems, and information formatting, so the challenge for the GEOSS Capacity Building Working Group is strong and the task is only just beginning.

\section{References}

GEO. (2017). Group on Earth Observation. Retrieved 2017, www.earthobservation.org

Lovison L., Parodi L., Monett A., Dueñas P., Frye S., Nativi S. \& Santoro M, (2016) - A GEOSS Architecture Implementation Pilot Project for Disasters in Chile. Photogrammetric Engineering \& Remote Sensing, 7985.

Nativi S., Craglia M., \& Pearlman J. (2013) - Earth science infrastructures interoperability: The brokering approach. IEEE JSTARS, 118-1129.

Santoro M., Mazzetti P., Nativi S., Fugazza C., Granell C. \& Diaz L. (2012) - Methodologies for augmented discovery of geoespatial resources. Discovery of Geospatial Resources: Methodologies, Technologies and Emergent Applications, Laura Diaz, Carlos Granell 
\& Joaquin Huerta eds. 172-203.Hershey, PA:

Information Science Reference. 